\title{
FIGO Grade 2 Endometrial Endometrioid Adenocarcinoma
}

National Cancer Institute

\section{Source}

National Cancer Institute. FIGO Grade 2 Endometrial Endometrioid Adenocarcinoma. NCI Thesaurus. Code C40147.

A primary endometrioid adenocarcinoma of the endometrium that contains $6-50 \%$ nonsquamous solid areas. 